University of Nebraska - Lincoln

DigitalCommons@University of Nebraska - Lincoln

7-2009

\title{
Preface to the 18th annual ASHA-NIH research symposium: Neurobiological determinants of communication development
}

Steven M. Barlow

University of Kansas, steven.barlow@unl.edu

Jordan R. Green

University of Nebraska-Lincoln, jgreen4@unl.edu

Follow this and additional works at: https://digitalcommons.unl.edu/specedfacpub

Part of the Special Education and Teaching Commons

Barlow, Steven M. and Green, Jordan R., "Preface to the 18th annual ASHA-NIH research symposium: Neurobiological determinants of communication development" (2009). Special Education and Communication Disorders Faculty Publications. 49.

https://digitalcommons.unl.edu/specedfacpub/49

This Article is brought to you for free and open access by the Department of Special Education and Communication Disorders at DigitalCommons@University of Nebraska - Lincoln. It has been accepted for inclusion in Special Education and Communication Disorders Faculty Publications by an authorized administrator of DigitalCommons@University of Nebraska - Lincoln. 


\title{
Preface to the 18th annual ASHA-NIH research symposium: Neurobiological determinants of communication development
}

\author{
Steven M. Barlow \\ Department of Speech-Language-Hearing: Sciences \& Disorders, \\ Programs in Neuroscience, Human Biology \& Bioengineering, University of Kansas, \\ 1000 Sunnyside Avenue, University of Kansas, Lawrence, KS 66045, USA; email smbarlow@ku.edu \\ Jordan R. Green \\ Department of Special Education and Communication Disorders, \\ 318 O Barkley Center, University of Nebraska-Lincoln, Lincoln, NE 68583-0738, USA
}

Neurobiological studies of the mammalian brain in health and disease have contributed greatly towards an improved understanding of the maturation-dependent vulnerability of the late preterm brain, the plasticity of the immature nervous system, and the evolution of specialized mechanisms for a communication or 'language-ready' neural substrate. Advances in developmental neurobiology have important implications for speech-language pathologists and audiologists working with neonates who, by virtue of their prematurity, are at risk for developmental disabilities. The extrauterine environment during this critical period (24-40 weeks gestation) in brain development has a profound and long lasting impact on the premature infant. Prior barriers to research on very young children and infants have recently been overcome with the development of non-invasive techniques for neuroimaging and recording biological events. Researchers from a variety of disciplines are now using these techniques to derive knowledge about early communication development, and to evaluate the efficacy of treatments designed to facilitate early communication and feeding development. The 18th annual research symposium, co-sponsored by the American Speech-Language-Hearing Association (ASHA) and the National Institutes of Health (NIH-NIDCD), was convened on November 21st, 2008 in Chicago, Illinois. The title of this day-long symposium was Neurobiological Determinants of Communication Development, with a special focus on prematurity, developing brain, plasticity, early childhood, and neurodevelopmental outcome. This meeting provided ASHA attendees with a showcase of innovative methods for early detection of brain and behavioral anomalies in the premature infant, introduced translational research on mechanisms of plasticity to improve auditory function, and considered evidence on the specialized nature of mirror neuron brain systems to support the acquisition of language. This symposium featured four internationally recognized scholars including Amit Mathur, MD (Washington University), Ira Adams-Chapman, MD (Emory University), Michael Arbib, PhD (University of Southern California), and Anu Sharma, PhD (University of Colorado). The symposium also included a special session that featured the work of the following four early-career scientists whose research focuses on neurobiologic aspects of communication development: Meredith Estep, ABD (University of Kansas), Ignatius Nip, PhD (San Diego State University), Jayanthi Sasisekaran, PhD (University of Minnesota), and Ronald LeBel, ABD (University of Colorado). 
Dr. Amit Mathur reviewed major public health issues associated with prematurity. The incidence of preterm birth continues to grow annually and represents nearly $13 \%$ of all live births and is associated with the frequent occurrence of subsequent behavioral, neurological, and psychiatric challenges faced by surviving infants. He emphasized that cerebral palsy and cognitive impairments are frequent neurodevelopmental outcomes among very preterm children (born $<30$ weeks gestational age). These adverse outcomes are related to a confluence of abnormal brain development along with white and gray matter injury sustained during the neonatal period. Magnetic resonance imaging in the neonatal period and infancy provides a non-invasive, in vivo assessment of brain development and extent of brain injury. Striking examples of what can be achieved with serial MR imaging of the late gestation infant, including diffusion tensor tractography, magnetic resonance spectroscopy, cortical folding, and brain volumetrics clearly demonstrated that resources and technologies are available to map the extent and timing of injury (Mathur, Neil, McKinstry, \& Inder, 2008). These powerful new tools show great promise for improving the early identification of children who are in need of interventions that minimize the impact of brain injury acquired during late gestation.

The dynamics of brain development was further elaborated by Dr. Ira Adams-Chapman. She emphasized that brain assembly is characterized by critical periods of proliferation, maturation, and migration (Adams-Chapman, 2006). An improved understanding of the vulnerability of the immature brain will have important clinical implications. Cerebral, cerebellar, and deep brain nuclei serving motor and sensory functions for speech communication are highly vulnerable to injury secondary to oxidative stress, inflammation, hypoxia, and ischemia. During late gestation, the premature infant is predisposed to multiple factors related to their developmental immaturity that significantly increases the risk for brain injury and subsequent abnormal neurologic sequelae, including the risk for development of intraventricular hemorrhage (IVH) and periventricular leukomalacia (PVL), hypoxic respiratory failure, hyperbilirubinemia, and infection. Dr. Adams-Chapman reinforced that it is important to recognize that the late preterm brain is only a fraction of the full-term brain weight and a significant proportion of brain growth, development, and networking occurs during the last 6 weeks of gestation. During this critical time period of development, the nervous system is particularly vulnerable to injury, which may result in direct damage to developing tissues or disruption to critical pathways needed for neuronal or glial development.

Dr. Michael Arbib challenged symposium attendees by developing a series of arguments from experimental data in non-human primates and humans to propose the existence of a language-ready brain, which is interpreted to mean one that equips an infant to be able to learn a human language. As far as we know, Homo sapiens represent the only creature with such a brain. The original mirror system hypothesis (Arbib and Rizzolatti, 1997; Rizzolatti and Arbib, 1998) argued that the evolutionary basis for language parity (i.e., the same representations are used by talkers and listeners to transmit and perceive messages, respectively) is provided by the mirror system for grasping. According to Arbib, mirror neurons discharge both when the monkey makes hand movements of a specific kind (e.g., a precision pinch, or tearing paper) and when the monkey observes a human or monkey making more or less similar actions. In contrast to mirror neurons, canonical neurons are grasp-related neurons which fire during execution but not observation (see Rizzolatti \& Sinigaglia, 2008, for an excellent review of both macaque and related human data). As Arbib notes, the current evidence for mirror systems in humans is largely derived from neuroimaging studies of brain regions. Definitive evidence for mirror neurons in humans, however, will require single- and/or multi-cell recordings, like those that have been obtained in monkeys. Different brain regions (not individual neurons) may be implicated in the human brain as mirror systems for different classes of actions, and many researchers have attributed high level cognitive functions to human mirror regions such as imitation, intention attribution, and language (Rizzolatti \& Arbib, 1998). Arbib notes that even though monkeys are known to have mirror neurons, they do not imitate or learn language; therefore, attempts to attribute high-level cognitive functions to mirror neurons should proceed cautiously and in the 
context of functions served by linked brain regions. In essence, Arbib traces a path from praxis to communication, and presents convincing arguments to suggest that a language-ready brain resulted from the evolution of a progression of mirror systems and linked brain regions "beyond the mirror" that made possible the full expression of their functionality.

Dr. Anu Sharma described a fascinating series of studies on the deterioration, development, plasticity, and re-organization of the human central auditory pathways in normal hearing children and in deaf children who regain hearing after being fitted with cochlear implants (Sharma, Gilley, Dorman, \& Baldwin, 2007). Measures of central auditory maturation included cortical auditory evoked potentials (CAEP), high density electroencephalography (EEG), magnetoencephalography (MEG), and behavioral measures. Results using these and other brain imaging measures in humans and in animal models of deafness have established the existence of and time limits of a critical period for development of the central auditory pathways. Sharma noted that if stimulation is delivered within a period of 1.5-3.5 years, following binaural and monaural stimulation, respectively, CAEP latencies reach age-normal values within months following the onset of stimulation. However, if stimulation is withheld for more than 7 years, plasticity is reduced as evidenced by abnormal CAEP responses. This lack of central auditory development in congenitally deafened late-implanted children is correlated with relatively poor development of speech and language skills. Animal models suggest that primary auditory cortex may be functionally decoupled from higher-order auditory cortex, due to restricted development of inter- and intra-cortical connections, in congenitally impaired cats and children who have been deaf for long periods of time. Another aspect of plasticity that works against late-implanted children is the re-organization of higher order cortex by other sensory modalities (e.g., vision, somatosensation). Cortical re-organization may lead to, among other things, deficits in integration across different sensory modalities. A better understanding of cortical development and re-organization in children who experience auditory deprivation may have important clinical implications for intervention and habilitation of these children.

\section{Acknowledgments}

This work has been supported by the National Institute of Health, National Institute on Deafness and Other Communication Disorders, Grants DC R01 003311 and DC R01 006463.

\section{References}

Adams-Chapman, I. Neurodevelopmental outcome of the late preterm infant, Clinics in Perinatology 33 (2006), pp. 947-964.

Arbib, M. A., and G. Rizzolatti, Neural expectations: A possible evolutionary path from manual skills to language, Communication and Cognition 29 (1997), pp. 393-424.

Mathur, A. M., J. J. Neil, R. C. McKinstry, and T. E. Inder, Transport, monitoring, and successful brain MR imaging in unsedated neonates, Pediatric Radiology 38 (3) (2008), pp. 260-264.

Rizzolatti, G., and M. A. Arbib, Language within our grasp, Trends in Neuroscience 21 (5) (1998), pp. 188-194.

Rizzolatti, G., and C. Sinigaglia, Mirrors in the brain: How our minds share actions, emotions, and experience (Translated from the Italian by Frances Anderson), Oxford University Press, Oxford (2008).

Sharma, A., P. M. Gilley, M. F. Dorman, and R. Baldwin, Deprivation-induced cortical reorganization in children with cochlear implants, International Journal of Audiology 46 (9) (2007), pp. 494-499. 